\title{
ESTUDO DA INFLUÊNCIA DA HIDRATAÇÃO COMPLEMENTAR NAS PROPRIEDADES MECÂNICAS DE PELOTAS AUTORREDUTORAS
}

Felippe de Oliveira Sousa ' Giselle de Mattos Araújo '

\section{Resumo}

No presente trabalho investigou-se como diferentes meios e tempos de hidratação complementares, ou seja, hidratações realizadas após a produção, em pelotas autorredutoras afetam suas propriedades mecânicas. Para tal, pelotas idênticas foram confeccionadas pela adição de pellet feed, finos de carvão não-coqueificado, cimento e cal, e então foram submetidas a hidratação por imersão em água ou em câmara úmida, por tempos distintos. As pelotas foram então caracterizadas por meio de ensaios mecânicos de compressão e tamboramento, além de medição de microdureza ao longo do raio. Pelotas não hidratadas serviram de base para comparação dos resultados, que comprovaram o aumento na resistência à compressão das pelotas quando hidratadas e definiram o meio de hidratação por câmara úmida como mais eficiente.

Palavras-chave: Pelotas autorredutoras; Hidratação; Cura a frio.

\section{STUDY OF THE INFLUENCE OF COMPLEMENTARY HYDRATION ON THE MECHANICAL PROPERTIES OF SELF-REDUCING PELLETS}

\begin{abstract}
This study has investigated how different methods and time of complementary hydration affects the cold strength of self-reducing pellets. Identical pellets had been made by the addition of pellet feed, coal, cement and lime and have been subjected to hydration by water immersion or in a moist chamber for different periods. A group of non-hydrated pellets was used as reference for evaluation the effect of hydration. The pellets were then characterized by mechanical tests of compression and tumbling strength. The results have shown an increase in the mechanical properties of pellets and have proved that the hydration by moist chamber was the most efficient method
\end{abstract}

Keywords: Self-reducing pellets; Hydration; Green strength.

\section{INTRODUÇÃO}

A forte competição entre as empresas do setor Siderúrgico, aliada ao aumento do rigor da legislação ambiental, fez com que surgissem diferentes rotas de produção de aço, a liga metálica de maior importância e uso mundial, com processos distintos e de características peculiares, embora com iguais objetivos: maior produtividade a um menor custo respeitando os requisitos ambientais [I]. Dentre esses novos processos alternativos, o uso de pelotas autorredutoras vem ganhando destaque por permitir o aproveitamento de minérios de ferro de granulometria muito fina e carvões diversificados, que são aglomerados a frio com auxílio de algum aglomerante, como cimento, por exemplo, fazendo com que etapas de aglomeração a quente, frequentemente associadas a um alto custo e problemas ambientais, sejam desnecessárias. Aliado ao aproveitamento de matérias-primas mais baratas e resíduos metalúrgicos, a cinética de redução dessas pelotas apresenta uma vantagem quando comparada a cargas de minério como sínter e pelotas aglomeradas a quente, pois os gases redutores são gerados no interior da própria pelota e, por estar em contato com a carga a ser reduzida, podem diminuir o tempo total de redução. Apesar das vantagens citadas, a resistência mecânica das pelotas autorredutoras ainda se apresenta como dificuldade para sua utilização em reatores metalúrgicos comercialmente viáveis e um aumento em sua resistência mecânica acarretaria diminuição de perdas por quebra em transporte e manuseio das mesmas.

Atualmente as pelotas autorredutoras vêm sendo utilizadas em processos como Tecnored ${ }^{\circledR}$ e ITmk3, mas existem estudos para utilização de briquetes autorredutores

'Programa de Engenharia Metalúrgica e de Materiais, Instituto Alberto Luiz Coimbra de Pós-Graduação e Pesquisa de Engenharia, Universidade Federal do Rio de Janeiro - UFRJ, Rio de Janeiro, RJ, Brasil. E-mail: felippesousa@poli.ufrj.br 
como composição de cargas de altos-fornos e avaliação de suas consequências [2-4].

Com objetivo de avaliar a eficiência de métodos de hidratação complementares, pelotas autorredutoras foram confeccionadas manualmente pela adição de minério de ferro, carvão não-coqueificado, cimento Portland ARI (Alta resistência inicial), cal e água. Para efeito de comparação, as pelotas foram divididas em três grupos: não hidratadas, hidratadas por imersão e hidratadas em câmara úmida. Ensaios de caracterização de propriedades mecânicas como resistência a compressão e quebra volumétrica foram realizados por meio de ensaios de compressão e de tamboramento, além da medição de microdureza realizada ao longo do raio das pelotas.

\section{MATERIAIS E MÉTODOS}

As pelotas foram produzidas manualmente, conforme representado pela Figura I, através de mistura das matériasprimas: pellet feed, carvão não-coqueificado, cal e cimento. Uma mistura homogênea destes constituintes, com proporções definidas, foi realizada com auxílio de misturador. A configuração geométrica e a proporção da mistura utilizada na preparação são destacadas nas Tabelas I e 2, respectivamente.

Água foi adicionada à mistura para que as pelotas fossem produzidas. Seu papel é muito importante devido a seu efeito de capilaridade, que aglomera as matérias-primas e confere resistência inicial, essencial para sua modelagem.

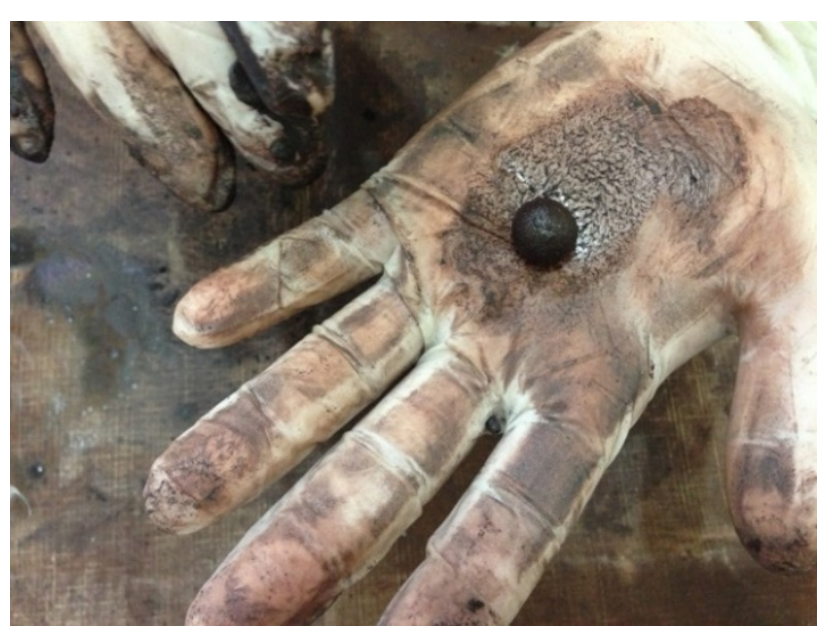

Figura I. Confecção manual das pelotas.

Tabela I. Configuração geométrica das pelotas

\begin{tabular}{cccc}
\hline $\begin{array}{c}\text { Raio } \\
(\mathbf{c m})\end{array}$ & $\begin{array}{c}\text { Volume } \\
\left(\mathbf{c m}^{3}\right)\end{array}$ & $\begin{array}{c}\text { Massa } \\
(\mathrm{g} / \text { unid })\end{array}$ & $\begin{array}{c}\text { Densidade } \\
\left(\mathbf{g} / \mathbf{c m}^{3}\right)\end{array}$ \\
\hline 0,6 & 0,91 & 2,96 & 3,27 \\
\hline
\end{tabular}

Tabela 2. Distribuição dos constituintes

\begin{tabular}{cccc}
\hline Pellet Feed & Carvão & Cal & Cimento \\
\hline $70,5 \%$ & $17,6 \%$ & $3,1 \%$ & $8,8 \%$ \\
\hline
\end{tabular}

Um total de 280 pelotas foram confeccionadas, as quais foram divididas em grupos. Cada grupo principal foi dividido em subgrupos menores, onde variou-se o tempo de hidratação, conforme mostrado na Tabela 3. Foram utilizadas efetivamente 25 pelotas para cada subgrupo, sendo $I 5$ pelotas usadas para o ensaio de tamboramento $e$ 10 para o ensaio de compressão a frio.

As pelotas não hidratadas, que serviram de base para avaliação da hidratação, foram curadas ao ar durante um período de 28 dias e então ensaiadas. As demais pelotas foram curadas ao ar por 7 dias após a hidratação $e$ então ensaiadas. Destaca-se dentre as pelotas imersas em água o grupo que foi hidratado por $10+10$ minutos. Esse grupo foi hidratado por 10 minutos e então curado ao ar por mais 3 dias e novamente hidratado por 10 minutos. $\mathrm{O}$ intuito desse procedimento foi verificar a influência de hidratações pausadas, que dão mais tempo as reações de hidratação ocorrer.

A Figura 2 representa a forma de hidratação das pelotas. Observamos a imersão plena das pelotas em água e a câmara úmida em seu interior. A humidade foi mantida em torno de $99 \%$ e temperatura controlada de $25^{\circ} \mathrm{C}$.

Os ensaios mecânicos foram escolhidos de acordo com a possível solicitação que as pelotas sofreriam em uso e transporte. Para tal foram selecionados, o ensaio de compressão a frio e de tamboramento.

O ensaio de compressão a frio é um ensaio de rotina utilizado em unidades pelotizadoras e que permite prever, com certa limitação, a força média de esmagamento suportada pelas pelotas. $O$ ensaio consiste em aplicar uma força por uma prensa com uma base plana, onde é colocada a pelota, até o seu esmagamento. A prensa utilizada para realização do ensaio foi equipada com célula de carga de $10 \mathrm{kN}$ e a taxa de avanço do cabeçote utilizada de $5 \mathrm{~mm} / \mathrm{min}$. $O$ teste transcorreu até que as pelotas fraturassem e a informação gerada no ensaio consistiu em um gráfico em força versus deslocamento do cabeçote. A Figura 3 representa o ensaio.

No ensaio de tamboramento utiliza-se um tambor de I metro de diâmetro equipado internamente com aletas, que elevam a carga até determinada altura e então caem sobre o tambor, de modo contínuo e repetitivo. Esse ensaio pode ser entendido como um ensaio de resistência à degradação por quebra volumétrica [2], embora também ocorra a quebra superficial. Os parâmetros do ensaio foram replicados para todos os tipos de pelota, onde a velocidade de rotação do moinho foi de 12,7 RPM durante 2 minutos. A Figura 4 representa esquematicamente o movimento das pelotas dentro do tambor.

Para a realização dos ensaios de microdureza vickers, as pelotas foram lixadas até metade do seu raio e então embutidas a frio, como pode ser visto na Figura 5. $O$ ensaio se baseia na resistência que o material oferece à penetração de uma pirâmide de diamante de base quadrada e ângulo entre as faces de $136^{\circ}$. Quanto mais eficiente à hidratação, maior a resistência à penetração da pirâmide e, consequentemente, maior a dureza encontrada. 
Tabela 3. Divisão de pelotas por grupo

\begin{tabular}{|c|c|c|c|c|c|c|c|c|c|}
\hline & $\begin{array}{c}\text { Não } \\
\text { hidratadas }\end{array}$ & & Imersã & em água & & & Câm & mida & \\
\hline $\begin{array}{l}\text { Hidratação } \\
\text { Complementar }\end{array}$ & - & 10 minutos & $\begin{array}{l}10+10 \\
\text { minutos }\end{array}$ & 20 minutos & 30 minutos & I dia & 2 dias & 5 dias & 7 dias \\
\hline
\end{tabular}
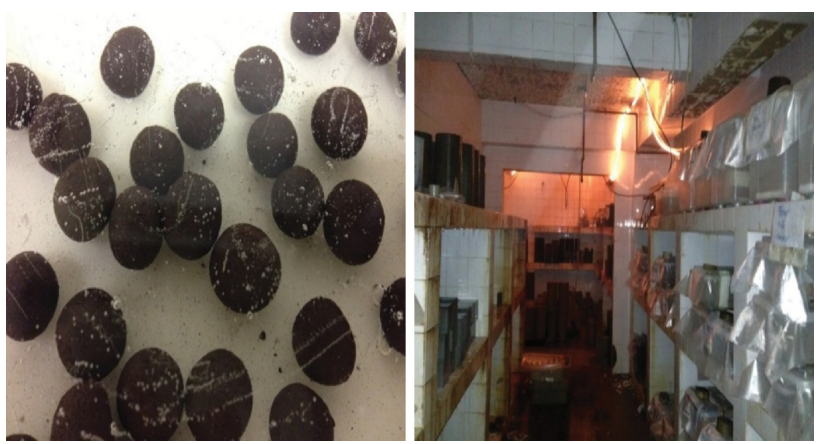

Figura 2. Hidratação das pelotas.

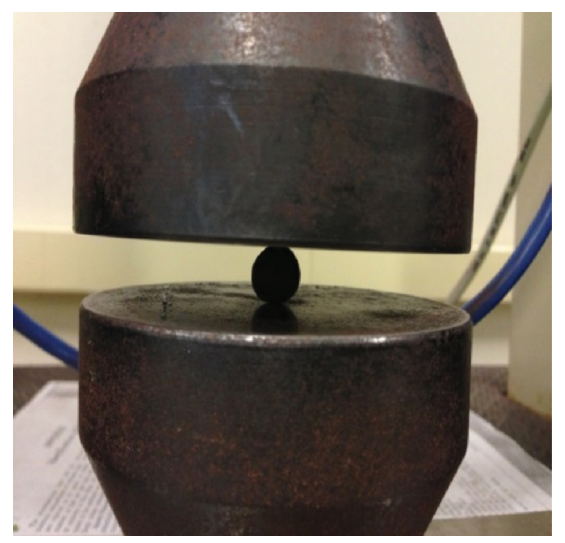

Figura 3. Ensaio de compressão a frio.
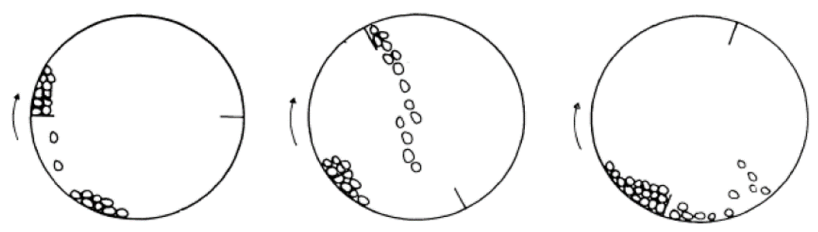

Figura 4. Representação esquemática do ensaio de tamboramento.

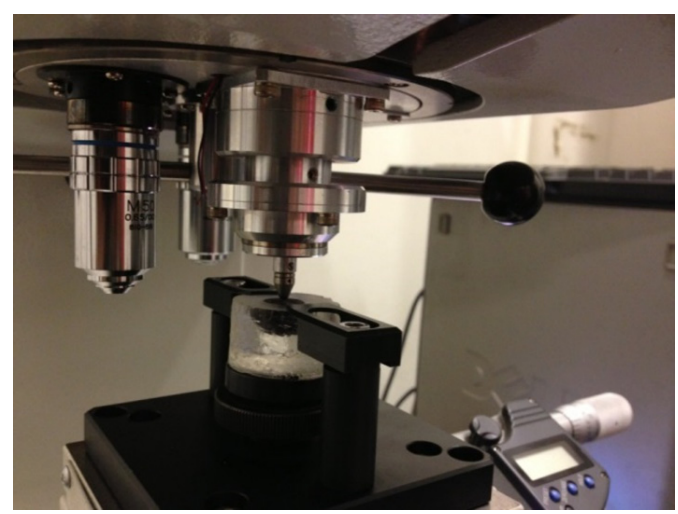

Figura 5. Pelota embutida a frio.

\section{RESULTADOS E DISCUSSÃO}

\section{I Cura a Frio}

Os mecanismos de cura das pelotas autorredutoras são fundamentais para compreensão dos fenômenos associados à hidratação. $\mathrm{A}$ cura dessas pelotas que utilizam cimento como aglomerante envolve uma reação de hidratação com a formação de um complexo de cálcio e silício tipo gel, assim como ocorre no concreto [3]. A reação de carbonatação também ocorre, mas a mesma pode ser desprezada devido ao pequeno tempo de cura encarado pelas pelotas e dado ao fato das pelotas serem feitas numa atmosfera normal, que representa baixa pressão parcial de $\mathrm{CO}_{2}$ [4].

O processo de hidratação do cimento é bastante complexo e consiste em várias reações distintas com a água. A taxa de hidratação vai depender desses componentes do cimento. $O$ cimento Portland apresenta em sua composição química compostos que contém cálcio, silicatos, aluminatos e outros óxidos e sulfatos, conforme mostrado na Tabela 4.

Quando adicionamos água às pelotas que contém cimento em sua composição, a reação de hidratação dos aluminatos, que podem ser basicamente definidos como aluminato de tri-cálcio, é extremamente rápida, da ordem de minutos - o que deve ser considerado muito rápido, haja vista que o cimento cura completamente com 28 dias - e muito exotérmica, formando compostos hidratados como $\mathrm{C}_{3} \mathrm{AH}_{6}, \mathrm{C}_{4} \mathrm{AH}_{19}$ e $\mathrm{C}_{2} \mathrm{AH}_{18}$ [5]. O gesso, formado basicamente por $\mathrm{CaSO}_{4}$ é adicionado à composição do cimento para retardadar essa cura muito rápida que inviabilizaria sua utilização. Após a neutralização dos aluminatos pelo gesso, o silicato de tri-cálcio assume a posição de principal componente a dar resistência mecânica durante a cura a frio.

A diferença entre a estrutura dos cristais explica as taxas de reação de hidratação mencionadas acima entre os di-cálcios e tri-cálcios silicatos. A estrutura cristalina dos tri-cálcios silicatos (a) é mais aberta que as do di-cálcio silicato (b), como pode ser visto na Figura 6, o que facilita sua hidratação.

Uma sequência cronológica simplificada da cura do cimento pode ser entendida como: Inicialmente ocorre com uma rápida reação, dentro de poucos minutos, seguida de um período de indução que leva entre 30 e 150 minutos para ocorrer. Durante esse período, um filme dos produtos hidratados é formado nas partículas de cimento e diminui a velocidade da hidratação de produtos coloidais. Em seguida a reação prossegue com a quebra do gel formado devido à diferença de pressão osmótica ditada pela diferença de concentração dos íons. Esse gel possui uma estrutura porosa 
Tabela 4. Componentes cimento Portland

\begin{tabular}{cc}
\hline Óxido & Componente \\
\hline $\mathrm{CaO}$ & $3 \mathrm{CaO} \cdot \mathrm{SiO}_{2}$ \\
$\mathrm{SiO}_{2}$ & $2 \mathrm{CaO} \cdot \mathrm{SiO}_{2}$ \\
$\mathrm{Al}_{2} \mathrm{O}_{3}$ & $3 \mathrm{CaO} \cdot \mathrm{Al}_{2} \mathrm{O}_{3}$ \\
$\mathrm{Fe}_{2} \mathrm{O}_{3}$ & $3 \mathrm{CaO} \cdot \mathrm{Al}_{2} \mathrm{O}_{3} \cdot \mathrm{Fe}_{2} \mathrm{O}_{3}$ \\
$\mathrm{MgO}$ & $4 \mathrm{CaO} \cdot 3 \mathrm{Al}_{2} \mathrm{O}_{3} \cdot \mathrm{SO}_{3}$ \\
$\mathrm{SO}_{3}$ & $3 \mathrm{CaO} \cdot 2 \mathrm{SiO}_{2} \cdot 3 \mathrm{H}_{2} \mathrm{O}$ \\
$\mathrm{H}_{2} \mathrm{O}$ & $\mathrm{CaSO}_{4} \cdot 2 \mathrm{H}_{2} \mathrm{O}$ \\
\hline
\end{tabular}

Fonte: Adaptado de Kasai et al. [4].
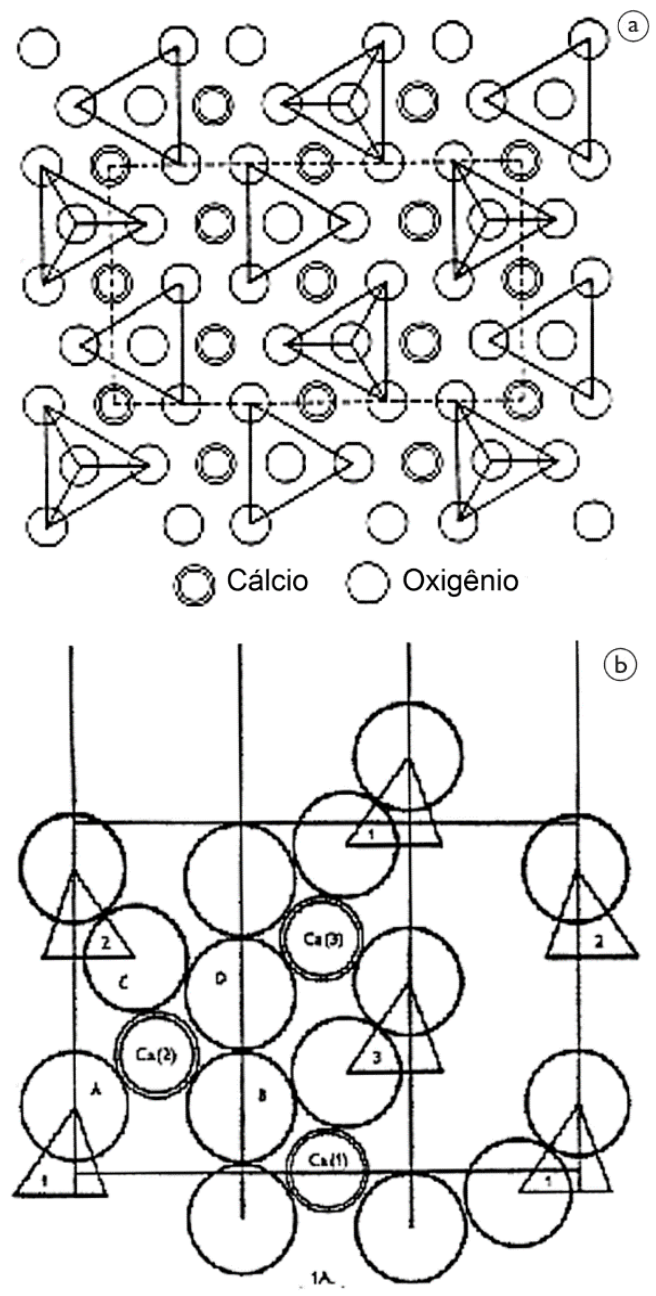

Figura 6. Estrutura cristalina.

e tende a alcançar uma fase termodinamicamente mais estável. Conforme os novos cristais de silicatos hidratados são formados as propriedades mecânicas dos aglomerados são melhoradas.

A evolução da resistência à compressão típica de cura de pelotas autorredutoras pode ser observada na Figura 7. Durante os primeiros dias de cura, o elevado aumento nas propriedades mecânicas é devido a fácil hidratação dos componentes do cimento. Essa primeira fase pode ser

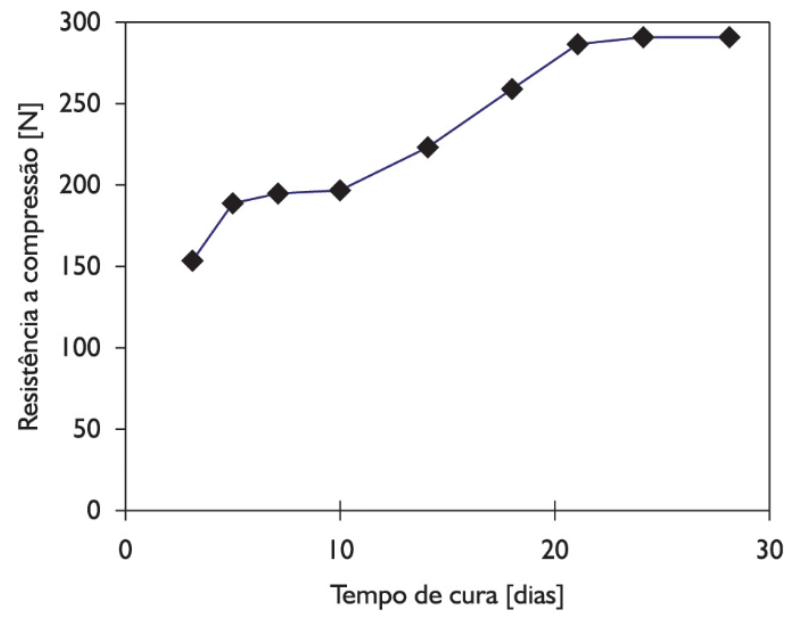

Figura 7. Evolução da resistência à compressão com o tempo de cura. Fonte: Adaptado de Kasai et al. [4].

definida como primeiro patamar. $\mathrm{O}$ segundo estágio do aumento da resistência à compressão pode ser atribuído a maior hidratação do di-cálcio silicato. A melhor resistência é alcançada normalmente dentro de 3 ou 4 semanas, como ocorre normalmente com o concreto [4].

\subsection{Autorredução}

Um amplo estudo de revisão da bibliografia dedicada a autorredução [6], abordando os fundamentos das reações e fenômenos envolvidos, a cinética, processos industriais, comportamento mecânico e uso de aglomerantes foi realizado.

A resistência mecânica em aglomerados autorredutores também foi abordada pelos pesquisadores visando elucidar os mecanismos que a envolvem. Foram relatadas experiências que envolvem o uso do carvão como aglomerante em briquetes fabricados pela compressão a quente nas matérias-primas pré-aquecidas, sendo que produto final é mais denso que as pelotas típicas, e possui resistência à compressão a frio da ordem de I kN.

Esforços também vêm sendo feitos no sentido de utilização dos aglomerados autorredutores. Ueda e colaboradores [5] desenvolveram modelo para prever o comportamento e as interações com os demais componentes da carga quando um aglomerado autorredutor é submetido às condições típicas de um alto-forno. Consideraram para tal que o aglomerado funciona a princípio como um micro reator. Um modelo matemático associando as diversas reações envolvidas foi proposto e testes experimentais da oxidação do carbono foram feitos em equipamento termogravimétrico. Os resultados mostraram que aqueles parâmetros já anteriormente identificados na literatura como sendo influentes (diâmetro de partícula, reatividade do redutor) mantém seu efeito. Outros parâmetros tais como a variação da composição da atmosfera ao redor da partícula também se mostraram importantes. Com relação à carga do forno como um todo, as avaliações apontaram que 
se na mistura à proporção $\mathrm{C} / \mathrm{O}$ aumenta, a taxa de reação aumenta, e pode-se então projetar uma fração ótima em função do desempenho desejado para a redução.

Takano e colaboradores [7] também investigaram os efeitos de se usar aglomerados autorredutores como parte da carga de um alto-forno. Para tal foram preparadas diferentes misturas contendo teores variados de carbono, e estas foram então testadas em um leito que combinou camadas de coque, sínter e pelota autorredutora, sob temperatura de $1.100^{\circ} \mathrm{C}$ e aplicação de carga. As amostras, que continham $10 \%$ de cimento como aglomerante passaram também por testes de resistência a frio. Os resultados mostraram que o uso de pelotas aglomeradas com o auxílio do cimento podem ser ferramentas promissoras na busca pela redução do consumo de carbono em altos-fornos, visto sua rápida redução. Além disso, o uso de pelotas com altos teores de carbono não só potencializou sua própria redução como também a dos sínteres que estavam em sua vizinhança. Levando em conta estes efeitos positivos associados às avaliações de resistência mecânica (antes e depois da redução), os autores concluíram que uma participação do carbono da ordem de $20 \%$ na mistura com o óxido de ferro é desejável.

\subsection{Ensaios de Compressão a Frio}

No grupo das pelotas imersas em água, o melhor resultado obtido foi para o grupo hidratado por $10+10$ minutos, com pausa de 3 dias. O motivo para tal está associado com a pausa da hidratação, que permite maior tempo para a ocorrência das reações de hidratações dos silicatos e aluminatos, conferindo assim maior resistência mecânica. Observa-se que as pelotas hidratadas por 10,20 e 30 minutos apresentaram resistência bastante próxima quando comparadas entre si, o que indica uma saturação da hidratação das pelotas, possivelmente associado a sua porosidade. Entretanto, quando comparamos esse resultado com as pelotas não hidratadas (base), observa-se significante aumento de sua resistência mecânica, confirmando uma prática de aumento de resistência das pelotas autorredutoras utilizável.

Depreende-se pela Figura 8 que as maiores médias de resistência à compressão foram obtidas por pelotas hidratadas em câmara úmida. Nesse grupo, as pelotas hidratadas por 5 dias se destacaram, atingindo uma média 3 vezes superior as pelotas não hidratadas (base). Uma queda bastante acentuada na resistência das pelotas é observada na hidratação por 7 dias. Tal fato se deve a saturação e posterior degradação das pelotas com o excesso de água. $O$ ponto ótimo de hidratação, portanto, encontra-se próximo a 5 dias.

\subsection{Ensaios de Tamboramento}

A análise dos resultados de ensaio de tamboramento se deu de maneira qualitativa, visto a baixa resistência das pelotas ao ensaio. $O$ único grupo que apresentou resistência de pelotas sem quebra foi o que também apresentou $\circ$ melhor resultado na compressão a frio, o de câmara úmida por 5 dias, onde 3 pelotas resistiram inteiras ao ensaio e as outras 12 se fragmentaram, conforme Figura 9.

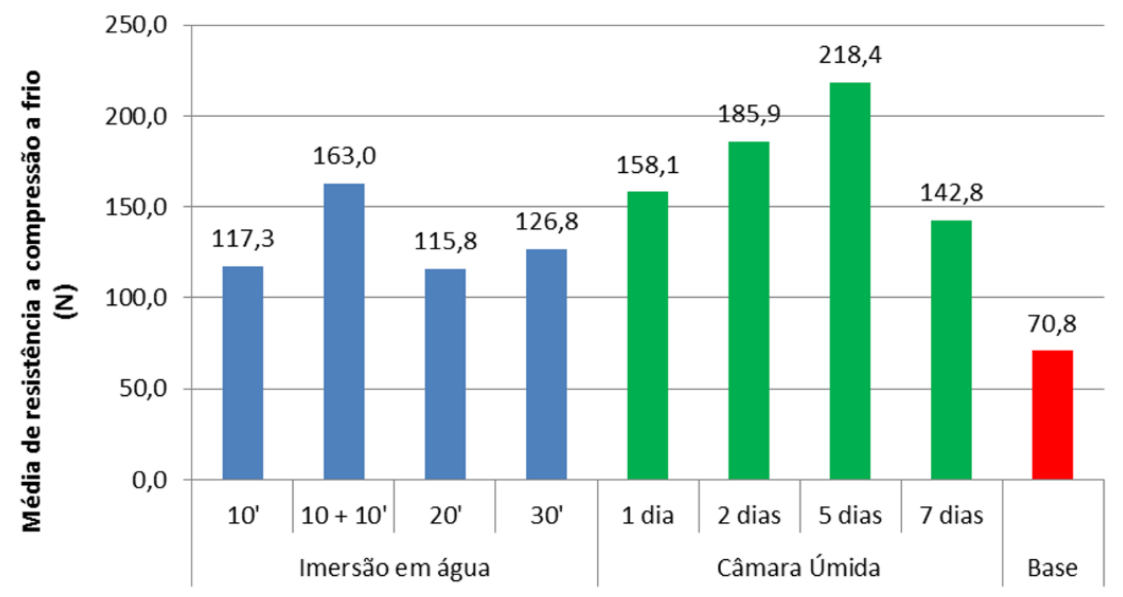

Figura 8. Média de resistência por tipo de pelota.
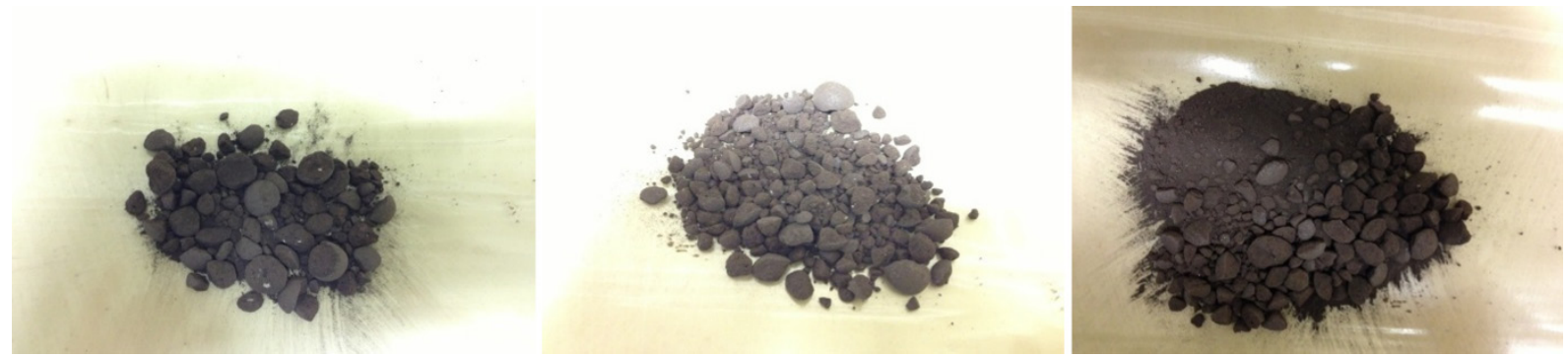

Figura 9. Pelotas após ensaio de tamboramento. 


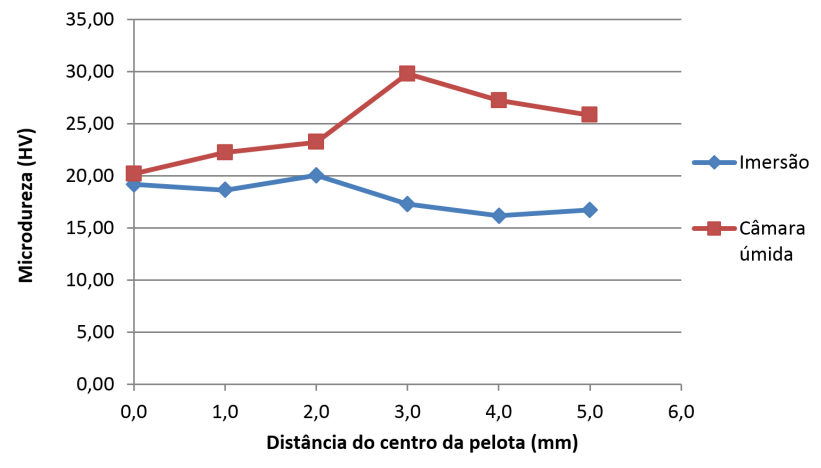

Figura 10. Microdureza ao longo do raio.

\subsection{Ensaio de Microdureza}

Os dois tipos de pelotas escolhidos para realização da microdureza vickers foram aquelas que apresentaram os maiores resultados de compressão a frio, ou seja, as hidratadas por $10+10$ minutos por imersão e hidratadas durante 5 dias em câmara úmida. As medições foram feitas no sentido vertical e horizontal a partir do centro para borda das pelotas, e então feito a média dos resultados. A Figura 10 apresenta os gráficos obtidos para cada tipo de pelota.

Analisando a Figura 10, observa-se uma constância dos resultados de microdureza para as pelotas que sofreram imersão, o que pode ser atribuído à saturação de água no interior da pelota. Diferentemente das pelotas que sofreram imersão, as que ficaram em câmara úmida por 5 dias apresentaram características de aumento da dureza em relação ao raio, ou seja, menores durezas foram encontradas no centro, onde menos água conseguiu penetrar no material, causando menos hidratação e então ficando menos resistentes. Pode-se, novamente, confirmar que as pelotas expostas por 5 dias em câmara úmida ainda não atingiram o ponto máximo de hidratação.

\section{CONCLUSÃO}

A análise dos resultados dos ensaios nas pelotas autorredutoras mostraram que:

- A hidratação complementar realizada nas pelotas, independente do tempo e do meio, contribuiu significativamente para o aumento da sua resistência;

- A hidratação por meio de uma câmara úmida se mostrou mais eficiente que aquela por imersão em água. A média de resistência à compressão para o melhor tempo de imersão em água foi de $163 \mathrm{~N}$, enquanto que para o melhor resultado de câmara úmida foi $218 \mathrm{~N}$. As pelotas não hidratadas apresentaram média de $7 \mathrm{IN}$;

- O aumento da resistência à compressão é diretamente proporcional à resistência a quebra volumétrica das pelotas;

\section{REFERÊNCIAS}

I D’Abreu JC, Mourão MB, Costa PHC, Noldi Júnior JH, Marcheze E. Curso de Auto redução carbo-metalotérmica. In: Anais do $7{ }^{\circ}$ Simpósio Brasil-Japão; 2008; São Paulo, Brasil. São Paulo: ABM; 2008.

2 Kasai A, Matsui Y. Lowering of thermal reserve zone temperature in blast furnace by adjoining carbonaceous material and iron ore. ISIJ International. 2004;44(I2):2073-2078. http://dx.doi.org// 0.2355/isijinternational.44.2073.

3 Matsui Y, Sawayama M, Kasai A, Yamagata Y, Noma F. Reduction behavior of carbon composite iron ore hot briquette in shaft furnace and scope on blast furnace performance reinforcement. ISIJ International. 2003;43(I2): I904-1912. http://dx.doi.org/10.2355/isijinternational.43. 1904.

4 Kasai A, Toyota H, Nozawa K, Kitayama S. Reduction of reducing agent rate in blast furnace operation by carbon composite iron ore hot briquette. ISIJ International. 20I I;5 I(8): I333-I335. http://dx.doi.org/I0.2355/ isijinternational.5I.I 333.

5 Goksel MA. Fundamentals of cold bond agglomeration process. In: Proceedings of the 2nd International Symposium on Agglomeration, Agglomeration 77; 1977; Berkley, EUA. Atlanta: K.V.S. Sastry; 1977. p. 877-900.

6 Litster JD, Waters AG, Nicol SK. Coke degradation by surface breakage in a modified tumble drum. Transactions ISIJ. 1987;27(I):3-9. http://dx.doi.org// 0.2355/isijinternational I 966.27.3.

7 Takano C, Mourão MB. Self-reducing pellets for ironmaking: mechanical behavior. Mineral Processing and Extractive Metallurgy Review: An International Journal. 2003;24(3-4):233-252. http://dx.doi.org// 0. 1080/7 I4856823.

Recebido em: 19 Ago. 2014

Aceito em: 21 Fev. 2015 